\title{
Pulling the plug on fax machines: can we improve the inpatient rheumatology referral system?
}

\author{
Authors: Roseanna Wheatley, Rachael Myers, Zenab Mateen, Arani Vivekanantham, Pippa Watson and \\ Jayne Little
}

\section{Introduction}

In an overstretched NHS with increasing workload pressures,' efficient interspecialty inpatient referral systems are important for patient safety and length of stay. Within Manchester University NHS Foundation Trust (MFT), referrals to rheumatology are handwritten, faxed to a secretary and put in the junior doctors' office. This system results in time delays, missing referrals and a lack of important patient information.

\section{Objective}

To review inpatient rheumatology referrals within two large teaching hospitals and identify areas within the current system that require improvement.

\section{Methods}

We performed a retrospective analysis of 105 inpatient rheumatology referrals over a time period of January 2018 to January 2019 from two hospitals within MFT. We established a list of items felt to be essential for an informative and safe referral and reviewed each paper referral against these criteria.

The medical notes of 28 patients; 17 from Manchester Royal Infirmary and 11 from Wythenshawe Hospital, were reviewed to establish the times of the first documentation of the need for a rheumatology review, the first fax received by rheumatology and the documentation of first rheumatology review.

\begin{tabular}{|c|c|c|}
\hline $\begin{array}{l}\text { Documentation of need } \\
\text { for rheumatology review } \\
\text { and date on fax referral } \\
\text { (median, (interquartile } \\
\text { range (IQR)/range)) }\end{array}$ & $\begin{array}{l}\text { Date on fax } \\
\text { referral and } \\
\text { rheumatology } \\
\text { review (median, } \\
\text { (IQR/range)) }\end{array}$ & $\begin{array}{l}\text { Documentation } \\
\text { of need for } \\
\text { rheumatology } \\
\text { review and } \\
\text { rheumatology } \\
\text { review (median, } \\
\text { (IQR/range)) }\end{array}$ \\
\hline $1(0-1 / 0-3)$ & $1(0-1 / 0-2)$ & $1.5(1-2 / 0-3)$ \\
\hline
\end{tabular}

\section{Results}

The inclusion of items of essential information from each hospital and the combined results are summarised in Table 1. Time of referral, referrer's contact details and patient's past medical history were the items most frequently omitted on the referrals reviewed.

The results in Table 2 demonstrate that on average, patients had a rheumatology review within 2 days of documentation of need for rheumatology review. The delay between fax date and the review was the same as that between a decision for referral being made and a fax referral being written.

Table 1. Inclusion of essential items for inpatient rheumatology referrals $n(\%)$

$\begin{array}{llll}\text { Item } & \text { Wythenshawe Hospital }(\mathbf{n}=\mathbf{1 0 5}) & \text { Manchester Royal Infirmary }(\mathbf{n}=\mathbf{1 0 5}) & \text { Combined }(\mathbf{n}=\mathbf{2 1 0}) \\ \text { Date of referral } & 78(74) & 95(90) & 173(82) \\ \text { Time of referral } & 26(25) & 7(7) & 33(16) \\ \text { Name of referrer } & 102(97) & 92(88) & 194(92) \\ \text { Referrer's contact details } & 38(36) & 13(12) & 51(24) \\ \text { Patient's name, hospital number } & 104(99) & 102(97) & 206(98) \\ \text { Patient location } & 95(90) & 101(96) & 196(93) \\ \text { Past medical history } & 62(59) & 75(75) & 137(65)\end{array}$

Authors: Manchester University NHS Foundation Trust ${ }^{*} \mathrm{RCP}$ chief registrar

\section{Conclusion}

The current system for inpatient rheumatology referrals is inefficient. Our results demonstrate that many of the referrals 
received by our rheumatology departments were missing essential information and there were significant delays in the receipt of referrals. We have undertaken a process mapping session to identify how this can be improved and an electronic referral system via the local electronic patient record (EPR) is being created. This should ensure that referrals are received in a timely manner and contain the correct information.

\section{Reference}

1 Royal College of Physicians. Underfunded, underdoctored, overstretched: The NHS in 2016. London: RCP, 2016. 